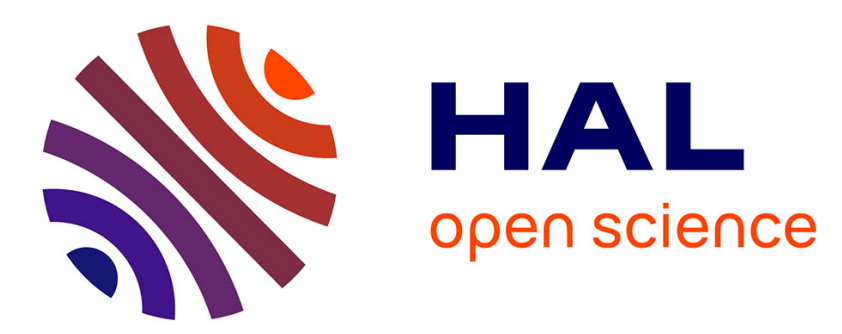

\title{
A method to detect broken bars in induction machine using pattern recognition techniques
}

Olivier Ondel, Emmanuel Boutleux, Guy Clerc

\section{To cite this version:}

Olivier Ondel, Emmanuel Boutleux, Guy Clerc. A method to detect broken bars in induction machine using pattern recognition techniques. IEEE Transactions on Industry Applications, 2006, 42 (4), pp.916-923. 10.1109/TIA.2006.876071 . hal-00140569

\section{HAL Id: hal-00140569 \\ https://hal.science/hal-00140569}

Submitted on 18 Apr 2007

HAL is a multi-disciplinary open access archive for the deposit and dissemination of scientific research documents, whether they are published or not. The documents may come from teaching and research institutions in France or abroad, or from public or private research centers.
L'archive ouverte pluridisciplinaire HAL, est destinée au dépôt et à la diffusion de documents scientifiques de niveau recherche, publiés ou non, émanant des établissements d'enseignement et de recherche français ou étrangers, des laboratoires publics ou privés. 


\title{
A Method to Detect Broken Bars in Induction Machine Using Pattern Recognition Techniques
}

\author{
Olivier Ondel, Emmanuel Boutleux, and Guy Clerc, Member, IEEE
}

\begin{abstract}
In this paper, a pattern recognition (PR) method is used to provide the tracking and the diagnosis of a system. First of all, from measurements carried out on the system, features are extracted from current and voltage measurements without any other sensors. These features are used to build up a pattern vector, which is considered as the system signature. Then, a feature selection method is applied in order to select the most relevant features, which define the representation space. The decision phase is based on the " $k$-nearest neighbors" $(\mathbf{k n n})$ rule, associated with an evolution tracking of system using trajectory allowing a diagnosis not only of states defined in the training set, but also of the intermediate states. The appearance of a new operating mode is taken into account in order to enrich the initial knowledge base and thus to improve the diagnosis. This approach is illustrated on asynchronous motor of $5.5 \mathrm{~kW}$ with squirrel cage, in order to detect broken bars under any load level. The experimental results prove the efficiency of PR methods in condition monitoring of electrical machines.
\end{abstract}

Index Terms-Fault detection and diagnosis, features selection, induction motor, $k$-nearest neighbors $(\mathrm{knn})$ rule, pattern recognition (PR).

\section{INTRODUCTION}

$\mathbf{T}$ HE MONITORING and diagnosis of electrical machines have been under focus for at least twenty years with a special interest in squirrel-cage three-phase induction machines [1]-[3].

Induction motors present numerous advantages due to their robustness and their power-weight ratio. Thus, they are widely used in the industry. Therefore, there is a considerable demand to reduce maintenance costs and prevent unscheduled downtimes for electrical drive systems, especially ac induction machine. Most of the recent research has been directed toward electrical monitoring of the motor in particular on inspecting a stator current.

Several methods and techniques can be used to detect induction machine faults. Some methods are described with details in [4]-[7]. Certainly, among these, the motor current signature

Paper IPCSD-06-026, presented at the 2005 IEEE International Symposium on Diagnostics for Electrical Machines, Power Electronics and Drives, Vienna, Austria, September 7-9, and approved for publication in the IEEE TRANSACTIONS ON INDUSTRY APPLICATIONS by the Electric Machines Committee of the IEEE Industry Applications Society. Manuscript submitted for review November 19, 2005 and released for publication April 2, 2006.

O. Ondel and E. Boutleux are with the Centre de Génie Electrique de Lyon, Ecole Centrale de Lyon, 69134 Ecully, France (e-mail: olivier.ondel@ ec-lyon.fr).

G. Clerc is with the Centre de Génie Electrique de Lyon, Université Claude Bernard-Lyon 1, 69622 Villeurbanne Cedex, France.

Digital Object Identifier 10.1109/TIA.2006.876071 analysis (MCSA) is a well-known approach for the detection and identification of faults in induction machine through their "signatures" over current signals. These methods are rather effective when the motor is supplied by electricity network. However, nowadays, more and more in the industrial applications, the asynchronous motor is associated with pulsewidthmodulation (PWM)-based drives in particular for the variation speed.

With this type of supply, the currents are affected by the multiple harmonics of the commutation frequency. This makes it almost impossible to detect of the faulty modes by current signature analysis. Moreover, the spectral lines do not exist with very weak load level. Furthermore, the analysis of these current lines could be ineffective to detect the appearance of other defects such as those related to the stator. For these reasons it is necessary to determine other features from various analyses (statistical analysis) [8], [9].

Finally, a wide range of features is necessary in order to identify the maximum of defects (electrical and mechanical).

Despite the various techniques mentioned above, the monitoring and fault detection of electrical machines have moved from the traditional techniques to artificial intelligence (AI) techniques in recent years [10]-[16]. Research trends show that AI techniques will have a greater role in electrical motor diagnostic system with advanced practicability, sensitivity, reliability, and automation.

Recent developments in hardware and software make it possible to produce a system for automatic condition monitoring of induction machines using signal processing and classification techniques for fault diagnosis. The most important point is that their design does not require a complete mathematical model of the induction motor.

In this context, this paper presents a diagnosis method based on a current measurement and a pattern recognition (PR) analysis. This method is used to detect and localize failures in induction motors. The aim is to identify automatically the operating conditions (faulty or not) under any level of load.

In Section II, an introduction to PR for diagnosis is done. The PR method is made in two phases. The first, named training phase, consists in determining the pattern vector (choice of the features sensitive to the defects), the representation space by features selection methods, the decision space (the classes) and in developing a decision rule. The second step, named working phase, consists in associating an unknown pattern with one of the defined classes, according to the decision rule.

An evolution tracking of various operating modes of the studied system is presented, just as the prediction of this evolution 
in order to obtain a more powerful diagnosis. Then, we will be able to characterize all the intermediate states between two classes.

Section III is devoted to knowledge updating, which corresponds to the recovery for analysis of rejected points in order to highlight the appearance of one or more new classes.

In Section IV, we apply our diagnosis method on a given system (asynchronous motor).

In Section V, results obtained are discussed. It presents the advantage of the diagnosis by PR method and the contribution of the evolution tracking of operating modes in the final classification.

\section{Diagnosis B Y PR}

The aim of statistical PR is to classify objects (patterns) by comparison with reference patterns gathered into classes (clusters) [17]. Such a decision system based upon PR requires an a priori knowledge of the studied process in order to define objects and classes. In statistical PR an object is a set of $d$ features $\left(x_{1}, x_{2}, \ldots, x_{p}, \ldots, x_{d}\right)$ represented as a point in the $d$-dimensional real space issued from these features. This space is named representation space. Thus, a pattern $i$ ( $i=1$ to $n$, $n$ being the total number of points composing the initial database), is characterized by a pattern vector (or a signature) $\underline{X}_{i}=$ $\left[x_{i 1}, x_{i 2}, \ldots, x_{i d}\right]$ which belongs to $\Re^{d}$. The classes or clusters $\left(\Omega_{1}, \Omega_{2}, \ldots, \Omega_{i}, \ldots, \Omega_{M}\right)$ are geometric areas of $\Re^{d}$ including similar reference patterns. The principle of the recognition is to determine with which class, among the $M$ known classes, to associate a new observed pattern $\underline{X}_{u}=\left[x_{u 1}, x_{u 2}, \ldots, x_{u d}\right]$.

The PR method is made in two phases. The first one, named training phase, consists in determining the representation space (a pattern vector), the decision space (the clusters), and developing a decision rule that produces boundaries between classes. The second one, named decision phase, consists in associating an unknown pattern with one of the defined clusters, according to the decision rule. The accuracy of PR is based on the relevance of the pattern vector, i.e., choice of features contained in this vector. Thus, in the following section, the features used to detect failures on our system are described.

\section{A. Relevant Signatures for Induction Machine Fault Monitoring}

In order to monitor the electric machine under a large number of defaults, a list of features is extracted from the current and voltage signal analysis, respectively, $I_{\mathrm{a}}, I_{\mathrm{b}}, I_{\mathrm{c}}$ and $V_{\mathrm{a}}, V_{\mathrm{b}}, V_{\mathrm{c}}$ [18], [19].

Twenty four features are extracted from the estimation of the positive sequences components of the lines voltages and currents (respectively $i_{d}$ and $v_{d}$ ).

1) Twenty two features are the amplitudes of harmonics, which are in the power spectrum of the current positive sequence component:

a) around the supply frequency $\left(f_{\mathrm{s}}\right)$

$$
f=f_{\mathrm{s}}(1 \pm 2 \cdot n \cdot g)
$$

b) around the principal slot frequencies

$$
f=f_{\mathrm{s}}\left[\frac{N_{\mathrm{r}}(1-g)}{p} \pm 2 \cdot m\right] \pm 2 \cdot k \cdot g \cdot f_{\mathrm{s}}
$$

where

$$
\begin{array}{ll}
n & 1,2 ; \\
k & 0,1 ; \\
m & 1 / 2,1,3 / 2 ; \\
g & \text { per unit slip; } \\
N_{\mathrm{r}} & \text { number rotor slot; } \\
p & \text { number of pole pairs. }
\end{array}
$$

2) Two features are given by

a) the current energy. For $C$ points in the spectrum, it is expressed as

$$
P_{1 d}=\frac{1}{C} \cdot \sum_{k=1}^{C}\left|i_{d}(k)\right|^{2}
$$

b) the direct impedance $\left(Z_{d}\right)$.

Considering the fast Fourier transforms, $I_{d}(f)$ and $V_{d}(f)$ of $i_{d}$ and $v_{d}$, respectively, $f$ being the frequency, $Z_{d}$ is calculated. It is the ratio between the fundamental components of $V_{d}$ and $I_{d}$

$$
Z_{d}=\frac{V_{d}\left(f=f_{\mathrm{s}}\right)}{I_{d}\left(f=f_{\mathrm{s}}\right)} \quad \text { with } f_{\mathrm{s}}: \text { supply frequency. }
$$

Most of the faults produce different sensitive frequency harmonics. However, some of them (stator faults) require other investigations. For that, the Park's transformation was applied on the currents and the voltages in order to calculate others features.

Eight features are extracted with the help of Park's vector approach [20] that is based on a two-dimensional representation of the three-phase components of the stator current. As a function of main phase-variables $\left(I_{\mathrm{a}}, I_{\mathrm{b}}, I_{\mathrm{c}}\right)$, the current Park's vector components are called $i_{\mathrm{s} \alpha}$ and $i_{\mathrm{s} \beta}$. Thus, we can write

$$
\left\|\overrightarrow{I_{\mathrm{s} \alpha, \beta}}\right\|=\sqrt{i_{\mathrm{s} \alpha}^{2}+i_{\mathrm{s} \beta}^{2}} .
$$

In the same way the modulus of the voltage is given by

$$
\left\|\overrightarrow{V_{\mathrm{s} \alpha, \beta}}\right\|=\sqrt{v_{\mathrm{s} \alpha}^{2}+v_{\mathrm{s} \beta}^{2}} .
$$

1) Five features are calculated from the currents. The peakto-peak values of $i_{\mathrm{s} \alpha}$ and $i_{\mathrm{s} \beta}$ denoted $\delta_{\alpha}$ and $\delta_{\beta}$, respectively, and the standard deviation of $\left\|\overrightarrow{I_{\mathrm{s} \alpha, \beta}}\right\|, i_{\mathrm{s} \alpha}$ and $i_{\mathrm{s} \beta}$ named, respectively, $\sigma_{\mathrm{s}}, \sigma_{\alpha}$, and $\sigma_{\beta}$.

2) Three other features are determined from active and reactive powers ( $P$ and $Q$, respectively), which are calculated with voltages and currents Park's components [21]

$$
\begin{aligned}
& P=v_{\mathrm{s} \alpha} \cdot i_{\mathrm{s} \alpha}+v_{\mathrm{s} \beta} \cdot i_{\mathrm{s} \beta} \\
& Q=v_{\mathrm{s} \beta} \cdot i_{\mathrm{s} \alpha}-v_{\mathrm{s} \alpha} \cdot i_{\mathrm{s} \beta} .
\end{aligned}
$$

Reactive and active powers are normalized by the rms value of apparent power modulus $S=\sqrt{P^{2}+Q^{2}}$ and are denoted 
$Q^{\prime}$ and $P^{\prime}$. Their mean values $m_{q}$ and $m_{p}$ are calculated for each acquisition such as

$$
\begin{aligned}
& m_{p}=\frac{1}{N_{p}} \sum_{k=1}^{N_{p}} P^{\prime}(k) \\
& m_{q}=\frac{1}{N_{p}} \sum_{k=1}^{N_{p}} Q^{\prime}(k)
\end{aligned}
$$

where $N_{p}$ is the number of points in the signals.

Let $\underline{s}_{k}$ be one point of coordinates $\left(P^{\prime}(k), Q^{\prime}(k)\right)$ and $\underline{m}_{p, q}$ be the gravity center of this set point $\underline{m}_{p, q}=\left\lfloor m_{p} m_{q}\right\rfloor$.

Thus, the variation of the apparent power is the scalar defined by

$$
\zeta=\sum_{k=1}^{N_{p}}\left(\underline{s}_{k}-\underline{m}_{p, q}\right)\left(\underline{s}_{k}-\underline{m}_{p, q}\right)^{\mathrm{T}} .
$$

Finally, 32 features are determined. This set represents a list of indicator of multiple faults (electrical and mechanical faults). The feature set used as motor signature is further described in [19] and [22].

The disadvantage is that the high number of features can lead to a very large computing time. According to the various studied modes contained in the initial training set, it is possible that some of these features may be not really relevant or may be correlated. To correct these drawbacks, a feature selection method must be used in order to preserve only the most representative features for the studied faults [23]-[25]. Thus, the pattern vector will be fitted to the various faults contained in $X_{a}$.

\section{B. Pattern Vector Determination}

In [26], the authors present the advantages and drawbacks of the selection methods. According to the author, the sequential backward selection (SBS) is one of the most simple feature selection methods. However, this method is not the most perfect. Unlike the methods based on genetic algorithm (GA), it does not allow calculating all the possible combinations of $d^{\prime}$ features. Indeed, a comparative study between SBS method and a method based on GA was carried out in [27]. This paper showed that the two methods gave almost the same results for the selected features and for the level of classification. Thus, we chose to use SBS method because it requires less CPU time.

The objective is to seek, among $d$ initial features, a subset of $d^{\prime}$ features giving the most information. The features subset will have to maximize a criterion taking into account the separability/compactness of classes allowing a better discrimination of various operating modes.

For that the criterion is based on within-class scatter $S_{\mathrm{W}}$ and the between-class scatter $S_{\mathrm{B}}$ matrices whose expressions are as follows, respectively:

$$
\begin{aligned}
S_{\mathrm{W}} & =\frac{1}{n} \sum_{i=1}^{M} \sum_{j=1}^{n_{i}}\left(\underline{X}_{i j}-m_{i}\right)\left(\underline{X}_{i j}-m_{i}\right)^{\mathrm{T}} \\
S_{\mathrm{B}} & =\frac{1}{n} \sum_{i=1}^{M}\left(m_{i}-m\right)\left(m_{i}-m\right)^{\mathrm{T}}
\end{aligned}
$$

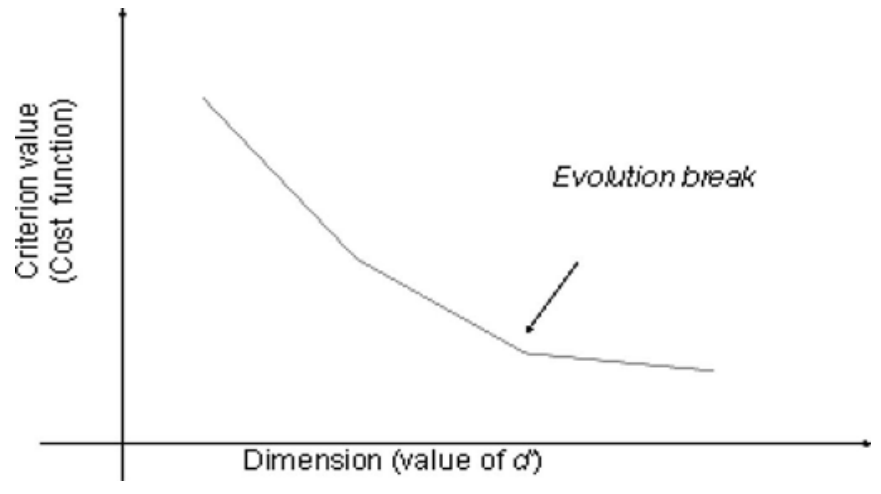

Fig. 1. Choice of the dimension of representation space.

where $M$ is the number of classes, $n_{i}$ number of samples in the class $\Omega_{i}, n$ the total number of samples, $m_{i}$ the gravity center of class $\Omega_{i}, \underline{X}_{i j}$ the $j$ th sample of class $\Omega_{i}$, and $m$ the general gravity center of the initial training set.

The criterion $J$ is directly linked to both above matrices

$$
J=\operatorname{trace}\left(S_{\mathrm{W}}^{-1} \cdot S_{\mathrm{B}}\right) .
$$

The SBS algorithm consists in deleting, at each step, the feature that penalizes the above criterion. This algorithm enables reducing the computing times by eliminating redundant or uninteresting information. This method requires knowing the partitioning of patterns contained in the initial training set in various clusters. Thereafter, the classification of a new observation, i.e., the diagnosis of the system state is strongly dependent on the selected features but also it can strongly depend on representation space dimension. Thus, the definition of this space dimension is also a key point because this value influences the final classification result. The ideal would be to determine simultaneously the best features and also the best dimension. For that, the criterion evolution used in SBS method according to the different values of $d^{\prime}$ is analysed.

Fig. 1 shows an example of the criterion value evolution. It allows determining the representation space dimension. Indeed, starting from a certain dimension, the addition of a feature does not bring any more information. Clearly, on Fig. 1, " $b$ " appears as the best dimension.

\section{Decision Phase: "k-nearest neighbors" (knn) Rule}

The decision rule is based on the knn rule. It allows deciding with which class among $M$ known classes $\left(\Omega_{1}, \Omega_{2}, \ldots, \Omega_{m}\right)$ to associate a new observed patterns $\underline{X}_{u}$.

The distance between all new form $\underline{X}_{u}$ and the training patterns $\underline{X}_{i}$ are computed as the following:

$$
d\left(\underline{X}_{u}, \underline{X}_{i}\right)=\left[\left(\underline{X}_{u}-\underline{X}_{i}\right) \cdot \Delta \cdot\left(\underline{X}_{u}-\underline{X}_{i}\right)^{\mathrm{T}}\right]^{1 / 2}
$$

where

$$
d\left(\underline{X}_{u}, \underline{X}_{i}\right)=\text { distance between the points } \underline{X}_{u} \text { and } \underline{X}_{i} .
$$

$\Delta$ is the identity matrix if the classical Euclidean distance is used or the inverse of the variance covariance matrix if Mahalanobis distance [28] is used. 


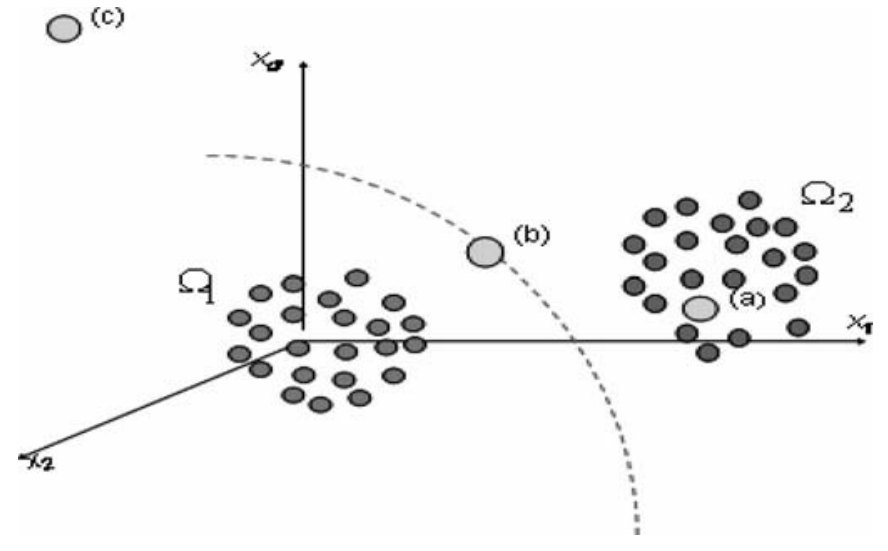

Fig. 2. Decision phase in PR system. (a) Affectation. (b) Ambiguity reject. (c) Distance reject.

The Mahalanobis distance is used for our application because it takes into account the dispersion of classes.

The Euclidean distance is more suitable when the defined classes have hyperspheric patterns with almost the same variance on each axis.

$\underline{X}_{u}$ will be assigned with the best-represented class among its knn.

In order to minimize the errors of classification, it is necessary to realize an adaptive diagnosis system, in which incomplete knowledge can be enriched. For that, the system must be able to include in its initial database, new operating modes, and to take into account the possible evolution of a number of classes.

In this purpose, two reject options [26], [29] are used, which allows avoiding automatic assigning of an unknown form to one of the classes (Fig. 2).

1) The ambiguity reject deals with the observations, which are near to the decision border between two classes. It copes with patterns that could belong equally to several classes: $\underline{X}_{u}$ is really assigned to $\Omega_{i}$ only if more than $k^{\prime}$ among its knn belong to $\Omega_{i}$, else $\underline{X}_{u}$ is rejected (with $k^{\prime}$ equals $k / 2$ ).

2) The distance reject is applied to patterns situated far from high-density areas. In other words, the distance between an unknown pattern $\underline{X}_{u}$ and its assigned class must be less than a defined threshold.

Assume that the class $\Omega_{i}$ is made up of $n_{i}$ points $\left(\mathrm{X}_{i j}\right.$, $\left.j=1 \ldots n_{i}\right) . m_{i}$ is the center of gravity of this class. Then, the distance reject rule is

$\left\{\begin{array}{l}\underline{X}_{u} \text { is rejected if } d\left(\underline{X}_{u}, m_{i}\right)>2 \cdot \max _{j=1, n_{i}}\left\lfloor d\left(\underline{X}_{i j}, m_{i}\right)\right\rfloor \\ \text { Else } \underline{X}_{u} \text { belongs to } \Omega_{i} .\end{array}\right.$

\section{Taking Into Account the Evolution of the Operating Modes}

The disadvantage of the previous method is that a new observation located between two classes can be rejected in ambiguity or distance, whereas it belongs to the same operating mode. Indeed, the training set being not exhaustive, it is impossible to have measurements with and without defect under any load level.

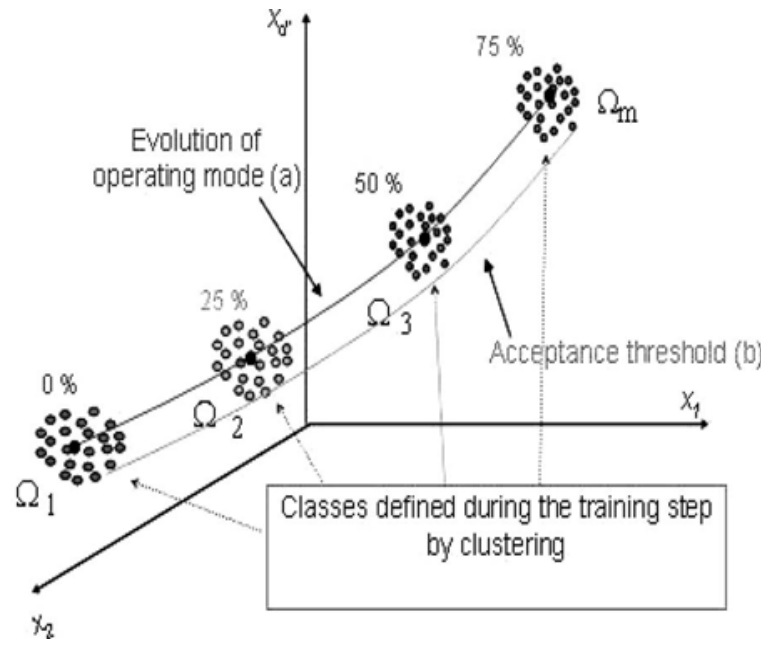

Fig. 3. (a)-(c) Representation of the trajectory of the operating mode concerned.

Thus, it is necessary to take into account the evolution of operating mode due to the level of load of the motor. A linear interpolation between the different centers of gravity of $L$ various classes of the same operating mode is applied. This leads to a function representing an $\langle\langle$ average trajectory $\rangle\rangle$ [Fig. 3(a)]. It is estimated by a mathematical function for each dimension. As this evolution is slow, the mathematical function used is a polynomial function with the following expression:

$$
x(d)=a(d)+\sum_{r=1}^{L-1}\left(b_{r}(d) z^{r}\right)
$$

where

$z \quad$ level of load;

$d \quad$ number of dimension $\left(i=1\right.$ to $\left.d^{\prime}\right)$;

$a_{d}, b_{d}$ coefficients determined for each dimension " $d$ ". These coefficients can be easily computed using a mean-square method;

$x(d) \quad d$ th component of the pattern vector.

The evolution of an operating mode is finally described by a function discretized every $1 \%$.

Let us consider an example of the motors application. A training set of healthy operation for various levels of load $(0 \%$, $25 \%, 50 \%$, and $75 \%$ of nominal load) (cf., Fig. 3) will be considered. The evolution function is then defined by

$$
x(d)=a(d)+b_{1}(d) \cdot z+b_{2}(d) \cdot z^{2}+b_{3}(d) \cdot z^{3} .
$$

Thus, the rejected points by the knn decision rule will be analysed according to this "trajectory." We are able to determine if a new observation $\underline{X}_{u}$ belongs to the same operating mode but with a different level of load.

As for the knn rule, a distance reject option was applied to avoid an assignment error. We will call it "trajectory of maximum dispersion." This one is determined according to the following way.

1) Starting from an operating mode made up of $L$ classes, we search, for each class, the furthest point from their respective center of gravity. It consists in determining the 
maximum dispersion of these classes. From the $L$ points, which are obtained, we estimate a mathematical function that will be used as acceptance threshold. This threshold is represented in the Fig. 3(b).

This reject can be summarized in the following way:

$$
\text { If } d\left(m_{i}, m_{\mathrm{n}}\right) \leq 1.5 * d\left(m_{i}, m_{i \max }\right) \quad \text { then } \mathrm{Nch}=i \%
$$

where

$m_{\mathrm{n}} \quad$ center of gravity of the new class or new observation;

$m_{i} \quad$ points of the $\langle\langle$ Evolution of operating mode $\rangle\rangle(i=$ $1, \ldots, 100)$;

$m_{i \max }$ points of $\langle\langle$ Acceptance threshold $\rangle\rangle \quad(i=1, \ldots$, 100);

Nch level of load of the new class or the new observation.

\section{KNOWLEDGE UPDATING}

The method of classification is a decision method with reject option (distance and ambiguity): some observations are classified and others rejected.

This knowledge updating phase corresponds to the reusing for analysis of the rejected points: there is, perhaps, a structure of these rejected set points highlighting one or more classes.

For that, the intraclass dispersion of the rejected points is taking into account.

From the rejected points, the intraclass dispersion $C_{\mathrm{r}}$ of the pseudo new class is determined, and then it is compared with average intraclass dispersion $C_{\mathrm{m}}$ of the classes defined in the training set. If $C_{\mathrm{m}}$ and $C_{\mathrm{r}}$ are nearly the same value then we have appearance of a new class.

The detection or the appearance of a new class can be summarized as follows:

Detection of new classes

1) Calculation of average compactness $C_{m}$ of the classes defined in the training set.

2) Calculation of the compactness of the rejected points $C_{\mathrm{r}}$.

3) Comparison of $C_{\mathrm{m}}$ and $C_{\mathrm{r}}$.

If $C_{\mathrm{r}} \leq 1.5 * C_{\mathrm{m}}$

Then Appearance of a new class

4) Human expertise to label the new class.

5) Integration of this new class in the training set.

\section{EXPERIMENTAL RESUlTS}

The asynchronous motor used for experimental investigation is a three-phase induction motor, $50 \mathrm{~Hz}, 4$ poles, $5.5 \mathrm{~kW}$, 11.4 A, and $1440 \mathrm{r} / \mathrm{min}$. The healthy squirrel-cage rotor is made of 28 bars.

As all AI methods, our method based on PR approach is based on an initial knowledge database named "training set." This set is defined in Table I.

In this table, two operating modes are studied: healthy mode and faulty mode with three broken bars. These operating con-
TABLE I

COMPOSITION OF INITIAL TRAINING SET

\begin{tabular}{|c|c|c|c|}
\hline Classes & \multirow{2}{*}{ Operating mode } & $\begin{array}{c}\text { Level of } \\
\text { load }\end{array}$ & $\begin{array}{c}\text { Numbers of } \\
\text { samples }\end{array}$ \\
\hline \multirow{2nnn}{*}{$\Omega_{1}$} & \multirow{3}{*}{ Healthy mode } & $0 \%$ & 10 \\
\cline { 1 - 2 } & & $50 \%$ & 10 \\
\cline { 4 - 4 }$\Omega_{3}$ & & $75 \%$ & 10 \\
\hline$\Omega_{4}$ & \multirow{2}{*}{$\begin{array}{c}\text { Faulty mode } \\
\Omega_{6}\end{array}$} & $0 \%$ & 10 \\
\hline$\Omega_{7}$ & (3 broken bars) & $25 \%$ & 10 \\
\hline$\Omega_{9}$ & & $75 \%$ & 10 \\
\hline
\end{tabular}

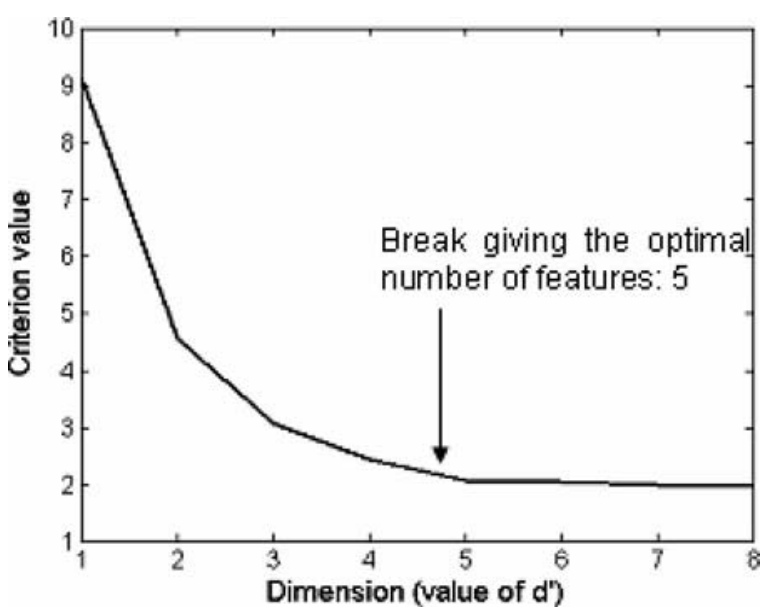

Fig. 4. Evolution of criterion value according to various values of $d^{\prime}$.

ditions are studied for four load levels: at no load, $25 \%, 50 \%$, and $75 \%$ of the nominal load. The total number of operating conditions is six: three for the healthy mode and three for the rotor having three broken bars.

For each functional state, 15 acquisitions of $10 \mathrm{~s}$, at $10 \mathrm{kHz}$, have been made in order to check the signature robustness. Among the 15 acquisitions, 10 are used to perform the training set. The five remaining constitute a test set being used to validate the performance of the diagnosis method (cf., Section IV-B). Thus, the training set is made of 60 samples, 10 by operating modes.

As we can seen in the Table I, the classes $\Omega_{2}$ and $\Omega_{8}$ corresponding to the healthy mode at $25 \%$ of load and faulty mode at $50 \%$ of load, respectively, have not been included into the initial training set, in order to show the utility of evolution tracking for each operating modes in the final diagnosis. The experiment is realized in two steps:

1) determination of the relevant features constituting the pattern vector;

2) assignment of test samples according to the decision rule (knn) described in Section II-C.

\section{A. First Step: Pattern Vector Determination}

Initially, it is composed of 32 features $(d=32)$.

As we have seen, classification varies according to the pattern vector dimension. While following the evolution of the criterion value, it is possible to determine automatically the value of $d^{\prime}$.

We note, on the Fig. 4, for $d^{\prime}=5$, the criterion value does not decrease any more to a significant degree. This break allows determining, without ambiguity, the choice of $d^{\prime}$. Increasing 
TABLE II

COMPARISON OF THE CRITERION VALUE FOR THE Two Methods With $d^{\prime}=5$

\begin{tabular}{|c|c|c|}
\hline & Genetic algorithm & SBS \\
\hline & $\mathrm{V}_{\mathrm{op}}=\left[\begin{array}{llll}\zeta & \mathrm{m}_{\mathrm{p}} \delta_{\alpha} & \sigma_{\beta} & \mathrm{Z}_{\mathrm{d}}\end{array}\right]$ & $\mathrm{V}_{\mathrm{op}}=\left[\begin{array}{lllll}\mathrm{m}_{\mathrm{p}} & \mathrm{m}_{\mathrm{q}} & \sigma_{\alpha} & \sigma_{\beta} & \mathrm{Z}_{\mathrm{d}}\end{array}\right]$ \\
\hline Criterion value & 2.0713 & 2.0756 \\
\hline $\begin{array}{l}\text { Computing time } \\
\text { (seconds) }\end{array}$ & 26.1 & 6.76 \\
\hline
\end{tabular}

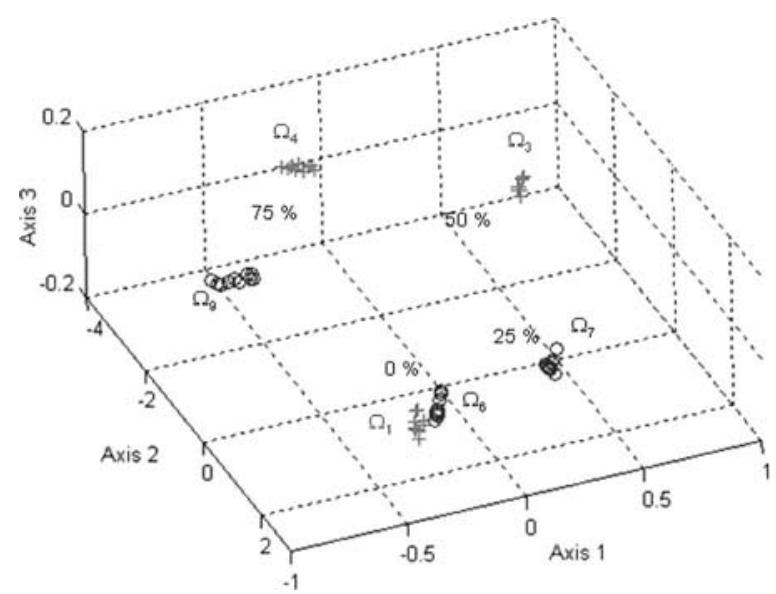

Fig. 5. Different classes representing the two states and their evolutions according to level of load (healthy rotor "+", three broken bars "O").

the value of $d^{\prime}$ will not bring any additional information on classification.

These results confirm that the evolution of the criterion value (13) is a simple and satisfactory solution to determine the dimension of the representation space.

The results in Table II are obtained on a computer unit "Advanced Micro Devices, Inc. (AMD) AthlonTM 64 processor 3000+" and $512 \mathrm{Mb}$ double-data-rate (DDR) RAM.

If we compare the pattern vector defined by SBS and GA method, the only difference is the choice of features $d^{\prime}$ (two different for $d^{\prime}=5$ ). The criterion value given by the two methods is nearly the same. On the other hand, the computing time with SBS is much lower than the GA one (decreasing of 75\%).

Thus, for this classification application, the pattern vector $V_{\text {op }}$ used, is this determined by SBS method

$$
V_{\mathrm{op}}=\left[\begin{array}{lllll}
m_{p} & m_{q} & \sigma_{\alpha} & \sigma_{\beta} & \mathrm{Z}_{d}
\end{array}\right]
$$

where

$$
\begin{array}{ll}
m_{p}, m_{q} & \begin{array}{l}
\text { mean values of active and reactive powers, nor- } \\
\text { malized by the rms value of apparent modulus; }
\end{array} \\
\sigma_{\alpha}, \sigma_{\beta} & \begin{array}{l}
\text { standard deviations of } i_{\alpha} \text { and } i_{\beta} \text { (currents Park's } \\
\text { vector components); }
\end{array} \\
Z_{d} & \begin{array}{l}
\text { direct impedance. It is the ratio between the fun- } \\
\text { damental components of } V_{d} \text { (voltage Park's vector } \\
\text { component) and } I_{d} .
\end{array}
\end{array}
$$

It is noted that the frequency components used as features

\begin{tabular}{|c|c|c|c|}
\hline Test sets & Operating mode & Load level & $\begin{array}{c}\text { Number of } \\
\text { samples }\end{array}$ \\
\hline $\mathrm{C}_{1}$ & \multirow{4}{*}{ Healthy mode } & $0 \%$ & 5 \\
\hline $\mathrm{C}_{2}$ & & $25 \%$ & 5 \\
\hline $\mathrm{C}_{3}$ & & $50 \%$ & 5 \\
\hline $\mathrm{C}_{4}$ & & $75 \%$ & 5 \\
\hline $\mathrm{C}_{6}$ & \multirow{4}{*}{$\begin{array}{l}\text { Faulty mode } \\
\text { (3 broken bars) }\end{array}$} & $0 \%$ & 5 \\
\hline $\mathrm{C}_{7}$ & & $25 \%$ & 5 \\
\hline $\mathrm{C}_{8}$ & & $50 \%$ & 5 \\
\hline $\mathrm{C}_{9}$ & & $75 \%$ & 5 \\
\hline
\end{tabular}
are not selected to form the optimal pattern vector. Indeed, they are ineffective to discriminate the different operating modes for weak load level (near to 0\%). That confirms they are less effective than the features extracted with the Park's vector approach (cf., Section II-A).
TABLE III

Presentation of the Various Test Sets

TABLE IV

Assignment Results of Test Set Healthy Patterns

\begin{tabular}{|c|c|c|c|c|}
\hline Test set & Healthy & Healthy & Healthy & Healthy \\
& $\mathrm{C}_{1}$ & $\mathrm{C}_{2}$ & $\mathrm{C}_{3}$ & $\mathrm{C}_{4}$ \\
& $0 \%$ & $25 \%$ & $50 \%$ & $75 \%$ \\
\hline Decision rule & & & & \\
associated with & $\begin{array}{c}3 / 5 \rightarrow \Omega_{1} \\
\text { trajectory }\end{array}$ & $5 / 5 \rightarrow \Omega_{2}$ & $5 / 5 \rightarrow \Omega_{3}$ & $5 / 5 \rightarrow \Omega_{4}$ \\
\hline
\end{tabular}

TABLE $\mathrm{V}$

Assignment Results of Test Set Faulty Patterns

\begin{tabular}{|c|c|c|c|c|}
\hline test set & $\begin{array}{c}\text { Faulty } \mathrm{C}_{6} \\
0 \%\end{array}$ & $\begin{array}{c}\text { Faulty } \mathrm{C}_{7} \\
25 \%\end{array}$ & $\begin{array}{c}\text { Faulty } \mathrm{C}_{8} \\
50 \%\end{array}$ & $\begin{array}{c}\text { Faulty } \mathrm{C}_{9} \\
75 \%\end{array}$ \\
\hline $\begin{array}{c}\text { Decision rule } \\
\text { associated with } \\
\text { trajectory }\end{array}$ & $5 / 5 \rightarrow \Omega_{6}$ & $5 / 5 \rightarrow \Omega_{7}$ & $5 / 5 \rightarrow \Omega_{8}$ & $5 / 5 \rightarrow \Omega_{9}$ \\
\hline
\end{tabular}

Fig. 5 shows the different classes in the best threedimensional space obtained from the principal components analysis (PCA) [30]. The three-dimensional space is a linear combination of the five features contained into the pattern vector.

In the second step, various test sets representing several operating modes are used to verify the fault detection capability of the diagnosis system.

\section{B. Second Step: Validation}

The data file for the test phase is made up of 40 samples, 5 by operating states. These 40 samples were not used to carry out the training phase. In this way, the training and test sets are always disjoined. Test sets are presented in the Table III.

The Tables IV and V present the assignment of the tests points $\underline{X}_{u}$ at a defined class in training set. This assignment is carried out by the decision rule associated with trajectory.

Concerning the healthy mode (cf., Table IV), only two measurements are badly affected. They are samples being located at $0 \%$ of load. That shows all the difficulty to dissociate these machine states for weak level of load. The five test points contained in $C_{2}$ representing the healthy mode at $25 \%$ of load are assigned to the class $\Omega_{2}$ corresponding to the healthy mode at $25 \%$. Normally, these points should have been rejected in distance because they are not represented in the initial training set. But using the evolution tracking (trajectories) (cf., Section II-D) they are well identified.

Concerning the faulty mode (cf., Table V), all the samples are well assigned. The five test points contained in $C_{8}$ representing the faulty mode at $50 \%$ of load are assigned to the class $\Omega_{8}$ corresponding to the faulty mode at $50 \%$.

The total classification rate $\left(T_{\mathrm{C}}\right)$ is: $T_{\mathrm{C}}: 38 / 40=95 \%$. 


\section{Discussion on the Results}

The use of a great set of features (signature of the system) versus a single indicator allows a better discrimination of the various operating modes. Indeed, this set represents a list of indicator of several faults (electrical and mechanical faults). Using this pattern vector, the application of a simple decision method (knn rule) allows obtaining very good classification result. Indeed, as the classes (representing the various operating modes) are well separated, it is easy to carry out the assignment of a new observation. Taking into account the evolution of each operating mode contained in the initial training set makes it possible to decrease the number of samples necessary for the training phase. Moreover, which allows classifying all new observation being located between two classes of the same operating mode but with a different level of load.

\section{CONCLUSION}

A diagnosis system based on PR was presented and applied to the detection of broken bars in an asynchronous motor. The knn rule, associated with the reject options was improved by taking into account the evolution of operating modes contained in the training set (trajectories). Now, this rule allows carrying out a more complete diagnosis by allowing us to label a new observation which belongs to an operating mode defined in the training set but being located between two classes (intermediate state). The updating of knowledge by the detection of new classes will allow packing the database (training set), and thus, progressively, obtaining a more complete labeling, and therefore a more powerful diagnosis. Finally, this technique will allow realizing a preventive maintenance ensuring the safety of the material and the personnel.

\section{REFERENCES}

[1] W. Deleroi, "Squirrel-cage motor with broken bar in rotor-Physical phenomena and their experimental assessment," in Proc. ICEM, Budapest, Hungary, Sep. 1982, vol. 3, pp. 767-771.

[2] A. J. Penman, J. C. Tait, and W. E. Bryan, "A software-based approach for machine condition monitoring," in Proc. Int. Conf. Electr. Mach. Des. and Appl., London, U.K., Sep. 1985.

[3] G. B. Kliman and R. A. Koegl, "Non-invasive detection of broken bars in operating induction motors," IEEE Trans. Energy Convers., vol. 3, no. 4, pp. 873-879, Dec. 1988

[4] G. A. Capolino, G. Cirrincione, M. Cirrincione, H. Henao, and R. Grisel, "Digital signal processing for electrical machines," in Proc. ACEMP, Kusadasi, Turkey, Jun. 2001, pp. 211-219. Invited Paper.

[5] F. Filippetti et al., "Development of expert system knowledge base to on-line diagnosis of rotor electrical faults of induction motors," in Proc. IEEE-IAS Аппи. Meet., Oct. 4-9, 1992, vol. 1, pp. 92-99.

[6] A. Bellini, F. Filippetti, G. Franceschini, C. Tassoni, and G. B. Kliman, "Quantitative evaluation of induction motor broken bars by means of electrical signature analysis," IEEE Trans. Ind. Appl., vol. 37, no. 5, pp. 1248-1255, Sep./Oct. 2001.

[7] R. Casimir, E. Boutleux, G. Clerc, and F. Chappuis, "Broken bars detection in an induction motor by pattern recognition," in Proc. Powertech, Bologna, Italy, Jun. 2003, vol. 2, pp. 282-288.

[8] M. E. H. Benbouzid, "A review of induction motors signature analysis as a medium for faults detection," IEEE Trans. Ind. Electron., vol. 47, no. 5, pp. $984-993$, Oct. 2000

[9] R. Casimir, E. Boutleux, G. Clerc, and A. Yahoui, "The use of features selection and nearest neighbors rule for faults diagnostic in induction motors," Eng. Appl. Artif. Intell., vol. 19, no. 2, pp. 169-177, Mar. 2006.

[10] F. Filippetti, G. Franceschini, C. Tassoni, and P. Vas, "Recent developments of induction motor drives fault diagnosis using AI techniques," IEEE Trans. Ind. Electron., vol. 47, no. 5, pp. 994-1004, Oct. 2000.
[11] D. Barros, M. Castilla, and J. C. Montano, "Wavelet and neural structure: A new tool for diagnostic of power system disturbances," IEEE Trans. Ind. Appl., vol. 37, no. 1, pp. 184-190, Jan./Feb. 2001.

[12] R. M. Tallam, T. G. Habetler, and R. G. Harley, "Continual on-line training of neural networks with applications in electric machines fault diagnosis," in Proc. IEEE 32nd Power Electron. Spec. Conf., 2001, pp. 2224-2228.

[13] M. Arkan, D. K. Perovic, and P. Unsworth, "Online stator fault diagnosis in induction motors," Proc. Inst. Electr. Eng.-Electr. Power Appl., vol. 148, no. 6, pp. 537-547, Nov. 2001.

[14] R. Casimir, E. Boutleux, and G. Clerc, "Fault diagnosis in an induction motor by pattern recognition methods," in Proc. SDEMPED, Atlanta, GA, Aug. 24-26, 2003, p. 294.

[15] M. Haji and H. A. Toliyat, "Pattern recognition-A technique for induction machines rotor broken bar detections," IEEE Trans. Energy Convers., vol. 16, no. 4, pp. 312-317, Dec. 2001.

[16] — - "Pattern recognition-A technique for induction machines rotor fault detections," in Proc. IEEE-IAS Anпи. Meeting, Chicago, IL, Sep. 30-Oct. 5, 2001, vol. 3, pp. 1572-1578.

[17] K. Fukunaga, Introduction to Statistical Pattern Recognition, 2nd ed. San Diego, CA: Academic, 1990.

[18] W. T. Thomson and M. Fenger, "Current signature analysis to detect induction motor faults," IEEE Ind. Appl. Mag, vol. 7, no. 4, pp. 26-34, Jul./Aug. 2001.

[19] R. Casimir, E. Boutleux, G. Clerc, and F. Chappuis, "Comparative study of diagnosis methods for induction motor," in Proc. Int. Conf. Electr. Mach. Brugge, Belgium, Aug. 25-28, 2002, pp. 465-470.

[20] S. M. A. Cruz and A. J. M. Cardoso, "Rotor cage fault diagnosis in three phase induction motors by Extended Park's Vector approach," Electr. Mach. Power Syst., vol. 28, no. 4, pp. 289-299, Apr. 2000.

[21] P. Vas, Electrical Machines and Drives, A Space Vector Theory Approach. New York: Oxford Univ. Press, 1992.

[22] R. Casimir, "Diagnostic des défauts des machines asynchrones par reconnaissance des formes," thèse, CEGELY l'Ecole Centrale de Lyon, Ecully, France, 2003

[23] A. K. Jain and D. Zongker, "Feature selection: Evaluation, application, and small sample performance," IEEE Trans. Pattern Anal. Mach. Intell., vol. 19, no. 2, pp. 153-158, Feb. 1997.

[24] F. J. Ferri, P. Pudil, M. Hatef, and J. Kittler, "Comparative study of techniques for large-scale feature selection," in Pattern Recognition in Practice IV, Multiple Paradigms, Comparative studies and Hybrid Syst., E. S. Gelsema and L. S. Kanal, Eds. Amsterdam, The Netherlands: Elsevier, 1994, pp. 403-413.

[25] A. Biem, S. Katagiri, and B.-H. Juang, "Pattern recognition using discriminative feature extraction," IEEE Trans. Signal Process., vol. 45, no. 2, pp. 500-504, Feb. 1997.

[26] M. Kudo and J. Sklansky, "Comparison of algorithms to select features for pattern classifiers," Pattern Recognit., vol. 33, no. 1, pp. 25-41, Jan. 2000.

[27] O. Ondel, E. Boutleux, and G. Clerc, "Feature selection by evolutionary computing: Application on diagnosis by pattern recognition approach," in Proc. 18th CAINE, Honolulu, HI, Nov. 2005, pp. 219-225.

[28] D. R. Wilson and T. R. Martinez, "Improved heterogeneous distance functions," J. Artif. Intell. Res., vol. 6, no. 1, pp. 1-34, 1997.

[29] P. A. Devijver and J. Kittler, Pattern Recognition, A Statistical Approach. Englewood Cliffs, NJ: Prentice-Hall, 1982.

[30] B. Pinkowski, "Principal component analysis of speech spectrogram images," Pattern Recognit., vol. 30, no. 5, pp. 777-787, 1997.

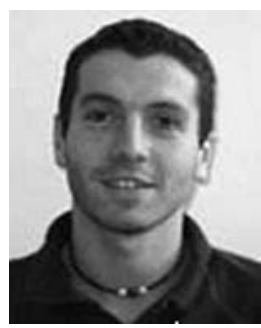

Olivier Ondel was born in Orange, France, on October 16, 1978. He received the Master degree in electrical engineering from the Université Claude Bernard-Lyon 1, Villeurbanne, France, in 2003. He is currently working toward the Ph.D. degree in the Department of Electrical Engineering, Ecole Centrale de Lyon, Ecully, France.

At the laboratory Centre de Génie Électrique de Lyon (CEGELY), his research interests are in fault diagnosis on a set of "converter-electrical machines" by means of pattern recognition (PR) methods. 


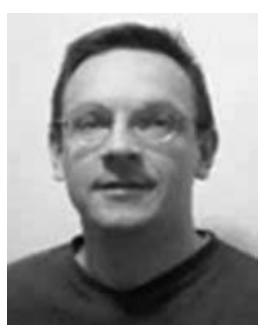

Emmanuel Boutleux was born on FrivilleEscarbotin, France, on July 1970. He received the Ph.D. degree in system control from the laboratory Heuristique et Diagnostic des Systèmes Complexes (HEUDIASYC), Compiègne, France, in 1996.

$\mathrm{He}$ is currently an Assistant Professor of Automatic Control at the Ecole Centrale de Lyon, Ecully, France. His research at the laboratory Centre de Génie Électrique de Lyon (CEGELY) includes diagnosis of complex systems by means of pattern recognition (PR) methods. He teaches automatica to engineering students.

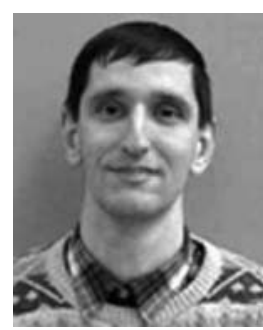

Guy Clerc (M'00) was born in Libourne, France, on November 30, 1960. He received the Engineer's and the Ph.D. degrees in electrical engineering from the Ecole Centrale de Lyon, Ecully, France, in 1984 and 1989, respectively.

$\mathrm{He}$ is a Professor at the Université Claude Bernard-Lyon 1, Villeurbanne, France, where he teaches electrical engineering. He carries out researches on control and diagnosis of induction machines at Centre de Génie Électrique de Lyon (CEGELY)/Université Claude Bernard-Lyon 1 (UCBL). 